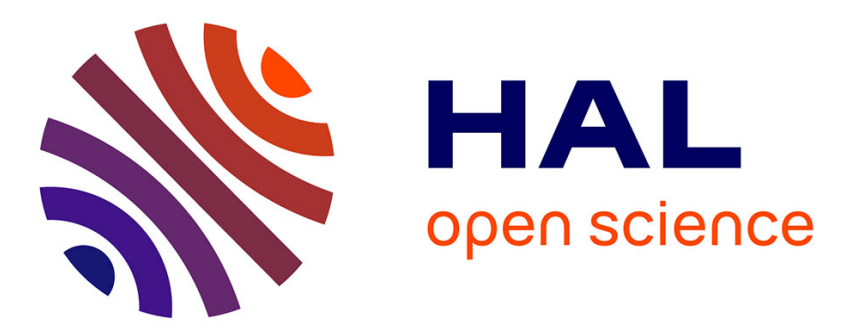

\title{
Molecular volume changes in cyanines. A laser-induced optoacoustic study
}

M. Churio, K. Angermund, S. Braslavsky

\section{To cite this version:}

M. Churio, K. Angermund, S. Braslavsky. Molecular volume changes in cyanines. A laserinduced optoacoustic study. Journal de Physique IV Proceedings, 1994, 04 (C7), pp.C7-323-C7-325. 10.1051/jp4:1994777 . jpa-00253306

\section{HAL Id: jpa-00253306 https://hal.science/jpa-00253306}

Submitted on 1 Jan 1994

HAL is a multi-disciplinary open access archive for the deposit and dissemination of scientific research documents, whether they are published or not. The documents may come from teaching and research institutions in France or abroad, or from public or private research centers.
L'archive ouverte pluridisciplinaire HAL, est destinée au dépôt et à la diffusion de documents scientifiques de niveau recherche, publiés ou non, émanant des établissements d'enseignement et de recherche français ou étrangers, des laboratoires publics ou privés. 
JOURNAL DE PHYSIQUE IV

Colloque C7, supplément au Journal de Physique III, Volume 4, juillet 1994

\title{
Molecular volume changes in cyanines. A laser-induced optoacoustic study
}

\author{
M.S. Churio, K.P. Angermund* and S.E. Braslavsky \\ Max-Planck-Institut für Strahlenchemie, 45413 Mülheim an der Ruhr, Germany \\ * Max-Planck-Institut für Kohlenforschung, 45466 Mülheim an der Ruhr, Germany
}

\begin{abstract}
The molecular movements taking place during the $E-Z$ photoisomerization of the carbocyanines 3,3'-diethyloxadicarbocyanine iodide (DODCI) and 3,3'-diethyloxacarbocyanine iodide (DOCI) were studied in ethanol-water mixtures using solvent- and temperature-dependent laser-induced optoacoustic spectroscopy (LIOAS) with nanosecond excitation and 1- $\mu$ s heat integration time. The contraction measured for the DODCI photoisomerization is attributed to solvent rearrangement around the DODCI isomers with different dipole moments, as evaluated using force field calculations. No volume change was observed for the DOCI photoisomerization $\left({ }^{1}\right)$.
\end{abstract}

\section{INTRODUCTION}

Photothermal techniques, in particular laser-induced optoacoustic spectroscopy (LIOAS) have been used for the determination of molecular movements concomitant with photoinduced reactions [1-4]. The proper selection of the heat integration time permits to assign the movement to a particular molecular step. The time can be selected from several picoseconds [5] to micro or milliseconds [1-4] depending on the particular technique used. With LIOAS, time windows from several ns to $\mu \mathrm{s}$ can be studied.

Callis et. al. [1] pointed out that there are two possible contributions to the volume change in a photoinduced reaction in solution: a) the difference in volume between products and reactants, and $\mathbf{b}$ ) the expansion or contraction of the medium upon release of heat. Only the second part depends on the thermoelastic parameters of the solution $\left(c_{p}\right.$, the heat capacity at constant pressure, $\beta$, the volume expansion coefficient, and $\rho$, the solution density). LIOAS measurements as a function of these parameters can separate both terms, thus allowing the calculation of molecular volume changes.

In order to test the potential and limitations of this type of measurements, we studied by LIOAS the photoisomerization of two symmetric carbocyanines in solution: 3,3'-diethyloxadicarbocyanine iodide (DODCl) and 3,3'-diethyloxacarbocyanine iodide (DOCI).

(1) The results presented in this contribution are part of the paper by the same authors in J.Phys. Chem. 98 (1994) 1776-1782. 


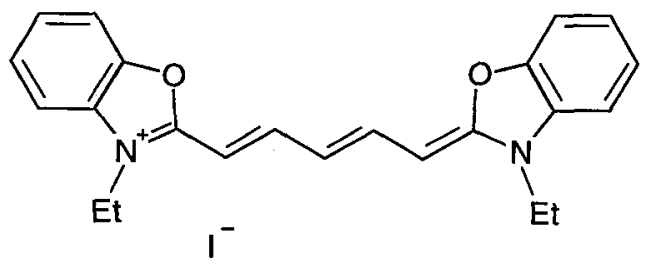

DODCI

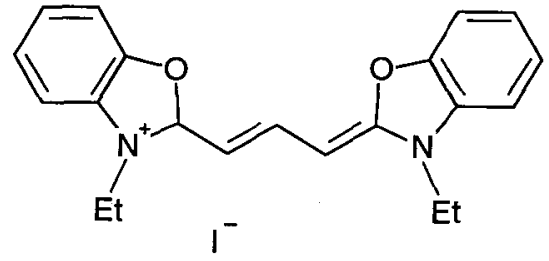

DOCI

\section{RESULTS AND DISCUSSION}

Upon irradiation, cyanines undergo a reversible $E-Z$ isomerization in their polymethynic chain. While the deactivation of the first excited state takes only a few ns, the photoisomer $\boldsymbol{P}$ is considered the final state in our measurements since the heat integration time in LIOAS (determined by the transit time of the acoustic wave through the laser beam diameter), was shorter than the lifetime of $\boldsymbol{P}$ in all cases and under all conditions studied (lifetimes in the range of ms). The absorption characteristics of $P$ and $N$, the normal state, are such that permit preferential excitation of $N$ when using wavelengths in the blue flank of the absorption spectrum of $N$. The absorption spectrum of $\boldsymbol{P}$ for DODCI was determined accurately by LIOAS [6]. The absorption spectrum of $\boldsymbol{P}$ for DOCI was determined in this work by flash photolysis with optical detection.

The solutions of DODCI and DOCI were excited with 8 ns dye laser pulses and the acoustic signal was measured with a piezoelectric ceramic. The amplitude of the signal was measured and the data evaluated as described in [7]. The amplitude of the optoacoustic signal depended in every case linearly on the laser energy. $\mathrm{CoCl}_{2}$, bromocresol green, and evans blue were used as calorimetric references [8].

Using simple energy balance considerations, the following expression is obtained which relates the ratio of the LIOAS energy-normalized signals $\left(\boldsymbol{H}_{\mathrm{n}}\right)$ for sample (s) and calorimetric reference (ref) with other parameters of the reaction:

$$
\frac{H_{n}^{s}}{H_{n}^{r e f}}+\Phi_{f} \frac{E_{f}}{E_{\lambda}}+\Phi_{N P} \frac{\Delta E_{N P}}{E_{\lambda}}=1+\frac{\Phi_{N P} \Delta V_{N P}}{E_{\lambda}}\left(\frac{c_{p} \rho}{\beta}\right)
$$

$\Phi_{\mathrm{f}}$ and $E_{\mathrm{f}}$ are the fluorescence quantum yield and emission maximum, respectively, $\Phi_{\mathrm{NP}}$ and $\Delta E_{\mathrm{NP}}$ are the isomerization quantum yield and the energy content of $\boldsymbol{P}$, and $\Delta V_{\mathrm{NP}}$ is the molar volume change occuring during the isomerization. $E_{\lambda}$ is the molar energy of the laser pulse.

Since $\beta$ in water or dilute aqueous solutions strongly depends on the temperature between $4^{\circ} \mathrm{C}$ and room temperature, and also appreciably increases on going from water to organic solvents, temperature- and solvent-dependent LIOAS experiments afford $\Delta V_{\mathrm{NP}}$ from the slope of the plot using the eq. above.

The fluorescence quantum yield was measured as a function of the temperature and solvent composition. The term accounting for the energy stored by the isomer (third term of the left hand side of the previous eq.) was calculated using the data determined in a previous work [6]. In any case this term accounted for less than $5 \%$ of the energy absorbed. The left hand side of the previous equation was plotted $v s\left(c_{p}\right.$ $\rho / \beta$ ). The variation of $\beta$ was achieved either by changing the temperature between $5-30^{\circ} \mathrm{C}$ in a $30 \%$ ethanol/water solution, or by changing the ethanol/water ratio at $25^{\circ} \mathrm{C}$. 
The value of $\left(c_{\mathrm{p}} \rho / \beta\right)$ for each solution and temperature was determined by using a calorimetric reference and measuring the compressibility factor, $\rho v_{\mathrm{a}}^{2}$, in each case.

For DODCI, the slope of the temperature-dependent plot afforded a value of $\Delta V_{\mathrm{NP}}=-29 \pm 12 \mathrm{ml} / \mathrm{mol}$ corresponding to a volume contraction of $48 \AA^{3} /$ molecule. Semiempiric calculations of the properties of the various possible configurational isomers of the dicarbocyanine revealed that the largest difference between them lies in their dipole moment. Thus, the molecular movement was attributed to solvent rearrangement around the isomers with different dipole moments. The configuration of $\boldsymbol{P}$ was assigned by comparison of the data obtained with the calculated energy content and dipole moment of the various possible configuration isomers. The linear regression for the solvent-dependent plot for DODCI was not good, indicating a change in solvation energy with different solvent composition.

For DOCI, a value $\Phi_{\mathrm{NP}} \Delta V_{\mathrm{NP}}=0$ was derived from the plots, both at variable temperature and at variable solvent composition. This could be the result of a too low value of the quantum yield (a value of $\Phi_{\mathrm{NP}}=0.012 \pm 0.007$ was determined using the comparative method in flash photolysis [9]) or a trully zero volume change. Assuming the latter, a provisional assignment of the photoisomer structure was made.

Acknowledgements: We are indebted to Professor Kurt Schaffner for his constant support of this work.

\section{References}

[1] Callis, J. B., Parson, W. W., and Gouterman, M., Biochim Biophys. Acta 267 (1972) 348-362.

[2] Hung, R. R. and Grabowski, J. J., J. Am. Chem. Soc. 114 (1992) 351-352.

[3] Herman, M. S. and Goodman, J. L., J. Am. Chem. Soc. 111 (1989) 1849-1854.

[4] Peters, K. S. and Snyder, G. J., Science 241 (1988) 1053-1057.

[5] Morais, J., Ma, J., and Zimmt, M.B., J. Phys. Chem. 95 (1991) 3885-3888.

[6] Bilmes, G.M., Tocho, J.O., and Braslavsky, S.E., J. Phys. Chem. 92 (1988) 5958-5962.

[7] Braslavsky, S.E. and Heihoff, K. (CRC-Handbook of Organic Photochemistry), Scaiano, J.C., ed., CRC Press, Boca Raton, Florida, 1989) Vol. 1, chapter 14.

[8] Braslavsky, S.E. and Heibel, G.E., Chem Rev. 92 (1992) 1381-1410.

[9] Bensasson, R.V., Goldschmidt, C.R., Land, E.J., and Truscott, T.G., Photochem. Photobiol. 28 (1978) 277-281. 